Macromolecular Nanotechnology

\title{
Nanocomposite hydrogels based on iota-carrageenan and maghemite: Morphological, thermal and magnetic properties
}

\author{
Diana José Maciel ${ }^{\mathrm{a}}$, Ivana Lourenço de Mello Ferreira ${ }^{\mathrm{a}, *}$, Geraldo Magela da Costa ${ }^{\mathrm{b}}$, \\ Manoel Ribeiro da Silva ${ }^{\mathrm{c}}$ \\ a Instituto de Química, Universidade do Estado do Rio de Janeiro, Rua São Francisco Xavier, 524, PHLC, sala 310, Maracanã, 20550-900 Rio de Janeiro, Brazil \\ ${ }^{\mathrm{b}}$ Departamento de Química, Universidade Federal de Ouro Preto, 35400 Ouro Preto, MG, Brazil \\ ${ }^{\mathrm{c}}$ Departamento de Física e Química, Instituto de Ciências, Universidade Federal de Itajubá, Itajubá, MG, Brazil
}

\section{A R T I C L E I N F O}

\section{Article history:}

Received 1 November 2015

Received in revised form 15 January 2016

Accepted 27 January 2016

Available online 28 January 2016

\section{Keywords:}

Magnetic hydrogels

Iota-carrageenan

Maghemite

Morphological properties

Magnetic properties

Thermal properties

\begin{abstract}
A B S T R A C T
The objective of this work was to prepare and characterize magnetic hydrogels based on iota-carrageenan, a polysaccharide obtained from biomass (Rodophyceae algae), containing maghemite $\left(\gamma-\mathrm{Fe}_{2} \mathrm{O}_{3}\right)$ nanoparticles. The morphological, thermal and magnetic properties of the hydrogels were evaluated, as well as the influence of the crosslinking agent $\left(\mathrm{CaCl}_{2}\right)$ at different concentrations $\left(0.3 \mathrm{~mol} \mathrm{~L}^{-1}\right.$ and $\left.0.5 \mathrm{~mol} \mathrm{~L}^{-1}\right)$ on the hydrogels' properties. The samples were characterized by scanning and transmission electron microscopy, vibrating sample magnetometry, thermogravimetry, Fourier-transform infrared spectroscopy and Mössbauer spectroscopy. The swelling degree of the hydrogels was also determined. The results showed that the synthesized magnetic material was mostly composed of $\gamma-\mathrm{Fe}_{2} \mathrm{O}_{3}$ and presented ferrimagnetic behavior. The hydrogels had spherical morphology and particle size in the range of $710 \mu \mathrm{m}$. The TEM images proved the magnetic particles had nanometric size. The hydrogels had good thermal stability and swelling degree in water of around 55\%. Both the magnetic nanoparticles and crosslinking agent $\left(\mathrm{Ca}^{2+}\right)$ were well distributed on the surface of the hydrogels. The samples responded to the stimulus of a magnet.
\end{abstract}

(c) 2016 Elsevier Ltd. All rights reserved.

\section{Introduction}

Hydrogels based on polysaccharides (biopolymers that are biorenewable resource, environmentally friendly) have been used in many fields because of their characteristics, such as biodegradability, biocompatibility, stimuli-responsive characteristics and biological functions making them a material of choice for many applications (including biomedical, toxic ion removal and water purification) [1-5]. Compared to their synthetic counterparts, renewable polymer-based materials offer a number of advantages especially regarding their environmental friendliness and low cost [6].

Among the polysaccharides, carrageenan stands out for its high capacity to absorb water, non-toxicity and abundance, since it is extracted from red algae $[7,8]$.

The carrageenans are a group of linear sulfated polysaccharides, present in the cell structure of Rodophyceae algae. Besides this source, Gigartinaceae produce Kappa $(\kappa)$ and Lambda $(\lambda)$ carrageenans, while Solieriaceae produce Kappa and Iota ( 1 ) car-

\footnotetext{
* Corresponding author.

E-mail addresses: dijmaciel@gmail.com (D.J. Maciel), ivanamello@uerj.br, ivanalmello@uol.com.br (I.L.M. Ferreira), magela@iceb.ufop.br (G.M. da Costa), manoel@pq.cnpq.br (M.R. da Silva).
} 
rageenans. All carrageenans have high molecular mass and are formed of alternating units of D-galactose and 3,6-anhydro-Dgalactose (3,6-AG) joined by $\alpha-1,3$ and $\beta-1,4$-glycosidic bonds [7-12].

The main differences between the types of carrageenan are the position and number of ester sulfate groups (3,6-anhydroD-galactose-n-sulfate). The content of 3,6-anhydro-D-galactose (3,6-AG) determines the characteristics among the carrageenan types and higher levels of ester sulfate imply smaller gelling force and lower solidification temperature [7,10,13].

Iota-carrageenan contains from $28 \%$ to $35 \%$ ester sulfate and $25 \%$ to $30 \% 3,6$-AG units. It has the particular feature of forming colloids and gels in aqueous media at very low concentrations. These gels are transparent and thermoreversible, and can have a wide range of textures, from highly elastic and cohesive to firm and brittle, depending on the combination of fractions utilized. In particular, $\mathbf{l}$-carrageenan (Fig. 1 ) is insoluble in cold water but is soluble in hot water $\left(\geqslant 60{ }^{\circ} \mathrm{C}\right)[8,13]$.

The characteristics of a nanocomposite are determined by the synergism between the intrinsic properties of the polymer and the properties of the inorganic particles that are added to the system. In this work, we prepared a polymeric nanocomposite with superparamagnetic properties composed of a polysaccharide (iota-carrageenan) and magnetic nanoparticles of iron oxide.

Superparamagnetism occurs when a material is composed of sufficiently small crystals with spins oriented in monodomains that can be considered as being thermodynamically independent particles. The magnetic moments of these monodomains affect the interaction of the unpaired electrons. The resulting magnetic moment becomes greater than that of a paramagnetic substance, and the specific magnetic sensitivity of these particles can substantially exceed the value of the corresponding soluble paramagnetic species due to this magnetic ordering $[15,16]$.

Superparamagnetic substances need remanent magnetization near zero when the magnetic field is removed, because the orientations of the monodomains return to being random. This means that the superparamagnetic iron oxide contrast agents will not aggregate due to the magnetic attraction [16].

The superparamagnetic property of a material is directly related to the size of its magnetic nanoparticles. Only particles with diameter smaller than $30 \mathrm{~nm}$ are superparamagnetic [15,17,18].

Nanoparticles of an iron oxide, such as maghemite $\left(\gamma-\mathrm{Fe}_{2} \mathrm{O}_{3}\right)$, are nontoxic, making them attractive for the preparation of polymeric materials with magnetic properties for use in many areas [16].

Therefore, this paper describes the preparation and characterization of nanocomposite hydrogels based on $\mathbf{t - c a r r a g e e n a n}$ and nanoparticles of $\gamma-\mathrm{Fe}_{2} \mathrm{O}_{3}$, crosslinked with $\mathrm{Ca}^{2+}$ ions. For this purpose, the morphological, thermal and magnetic properties of the hydrogels formed were evaluated. This research paper is of great importance; since it describes the preparation of a new hybrid polymeric material, eco-friendly, based on polysaccharide and iron oxide, which combines the characteristics of organic and inorganic compounds. Until now, were not found in the literature, works that deal with a systematic study on the preparation of magnetic hydrogels based on iota-carrageenan with spherical morphology. This type of carrageenan may provide a hydrogel with improved properties, because it contains a larger number of sulfate groups along its chain, which may lead to a more cross-linked polymeric network.

\section{Materials and methods}

The reagents used in this study were analytical grade (PA) and were used as received: ethanol $\left(\mathrm{C}_{2} \mathrm{H}_{6} \mathrm{O}\right)(\mathrm{Sumatex}$ Produtos Químicos Ltda.), iron (III) chloride $\left(\mathrm{FeCl}_{3}\right), 1 \%$ sodium hydroxide ( $\left.\mathrm{NaOH}\right)$, ammonium hydroxide ( $\left.\mathrm{NH} \mathrm{H}_{4} \mathrm{OH}\right)$, iron (II) sulfate $\left(\mathrm{FeSO}_{4}\right), 1 \%$ chlorhydric acid $(\mathrm{HCl}), 1 \%$ nitric acid $\left(\mathrm{HNO}_{3}\right)$ (Vetec Química Fina Ltda.), oleic acid $\left(\mathrm{C}_{18} \mathrm{H}_{34} \mathrm{O}_{2}\right)(\mathrm{B}$. Herzog Comércio e Indústria S.A.), iota-carrageenan (Iota-90 - Agargel Ltda.) and anhydrous calcium chloride $\left(\mathrm{CaCl}_{2} \cdot 2 \mathrm{H}_{2} \mathrm{O}\right)(\mathrm{Farmos})$.

\subsection{Synthesis of the magnetic material}

The magnetic material was synthesized by mixing the iron II and III salts using $\mathrm{NH}_{4} \mathrm{OH}$ as a base in a system composed of a three-neck round bottom flask, thermostatically controlled bath and mechanical stirrer. First, $14 \mathrm{~g}$ of iron sulfate was dissolved in a beaker containing $50 \mathrm{~mL}$ of distilled water, under magnetic stirring. In another beaker, $27 \mathrm{~g}$ of iron chloride was dissolved in $50 \mathrm{~mL}$ of distilled water, under magnetic stirring. These two solutions were then mixed in a three-neck round bottom flask with capacity of $500 \mathrm{~mL}$, under magnetic stirring, after which $130 \mathrm{~mL}$ of a solution of $\mathrm{NH}_{4} \mathrm{OH}(\mathrm{PA}$ grade) was added slowly, followed by $10 \mathrm{~mL}$ of oleic acid. The flask was placed in a thermostatically controlled silicon oil bath at $80^{\circ} \mathrm{C}$, under mechanical stirring for $30 \mathrm{~min}$ and the $\mathrm{pH}$ was measured. After this period, the mixture with the precipitate was left to cool slowly to room temperature and was washed with water and ethanol to remove the excess oleic acid.

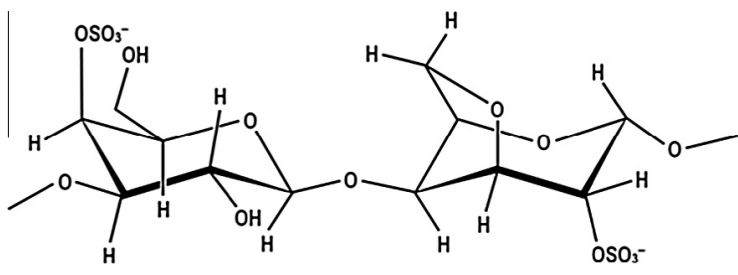

Fig. 1. Chemical structure of iota-carrageenan. 
The precipitate was separated by forced decantation by a magnetic field. The modified magnetic material was dried and stored in a flask in the dark and placed in a desiccator.

\subsection{Preparation of the magnetic carrageenan solution}

Two grams of iota carrageenan was mixed in $90 \mathrm{~mL}$ of distilled water at $60 \pm 5{ }^{\circ} \mathrm{C}$ until totally dissolved. Then the solution was cooled to $50 \pm 5{ }^{\circ} \mathrm{C}$ and the previously synthesized magnetic material was added, in a ratio of $2: 1$ by weight of carrageenan versus iron oxide, after which the solution was stirred until becoming homogeneous.

\subsection{Preparation of the magnetic carrageenan microspheres}

The hydrogels were prepared according to the method described by Nazarudin et al. [14]. The mixture containing the carrageenan and magnetic material was added dropwise at room temperature with a metering pump into a beaker containing the crosslinker solution $\left(\mathrm{CaCl}_{2}\right)$, at two concentrations $\left(0.3\right.$ and $\left.0.5 \mathrm{~mol} \mathrm{~L}^{-1}\right)$ (Supplementary material). The microspheres formed were left in contact with the crosslinker solution under gentle stirring for $3 \mathrm{~h}$.

After this process, the microspheres were filtered, washed with deionized water to remove the excess calcium ions and dried in an oven at $40{ }^{\circ} \mathrm{C}$. The dried hydrogels were characterized to evaluate their morphological, thermal and magnetic properties, as well as their swelling degree in water.

\subsection{Characterization}

The hydrogels were analyzed by Fourier-transform infrared spectroscopy (FTIR) to confirm the chemical composition. The analytic conditions were: KBR cell, resolution of $4.0 \mathrm{~cm}^{-1}$, accumulation of 4 scans and normal beam deflection. The morphology of the iron oxide nanoparticles and hydrogels was evaluated by granulometric analysis, scanning electron microscopy (SEM) and transmission electron microscopy (TEM). The granulometric analysis to determine the grain size distribution was performed with a Retsch AS 2000 basic vibratory sieve shaker, with sieves of 20, 24, 35, 48 and 60 mesh, equivalent to $850,710,425,300$ and $250 \mu \mathrm{m}$, respectively.

For the SEM analysis, the samples were covered with a fine gold layer to increase their conductivity and protect against localized heating. Secondary electron and X-ray detectors were used to capture the images and the acceleration voltages were 10 and $15 \mathrm{kV}$. For the TEM analysis, the samples were ground in an agate mortar with methyl alcohol. The supernatant was removed from the mortar and diluted in $1 \mathrm{~mL}$ of methyl alcohol and then submitted to ultrasound for $10 \mathrm{~min}$. A drop of the mixture was placed on a copper grid with carbon film. The STEM mode with EDX was used for chemical analysis, at voltage of $200 \mathrm{kV}$. The hydrogels were characterized by XRD to observe their crystalline structure and relate this with their chemical and physical properties. The following conditions were applied: power of $40 \mathrm{kV}$; current of $40 \mathrm{~mA}$; Cu K $\alpha$ radiation $(\lambda=1.9373) ; 2 \theta$ scan from $5^{\circ}$ to $45^{\circ}$.

The magnetic properties were analyzed with a vibrating sample magnetometer (VSM) calibrated with a nickel cylinder at room temperature (cycle time $=1 \mathrm{~s}$ and hysteresis cycle time $=10 \mathrm{~min}$ ). The following properties were evaluated: saturation magnetization, residual magnetization and coercivity. Each sample was weighed on an analytic balance with precision of $0.0001 \mathrm{~g}$. Then it was covered with insulation material to prevent contamination of the collector. The total time of analysis was 10 min and the magnetic field was varied from $15,000 \mathrm{G}$ to $-15,000 \mathrm{G}$. Each point was measured at intervals of $1 \mathrm{~s}$ : the magnetization was measured after $1 \mathrm{~s}$ and then the field was varied for the next measurement.

The Mössbauer spectroscopy was carried out at room temperature in constant acceleration mode with 1024 channels. The velocity was calibrated with a metallic iron absorber and the isomer shifts were related to $\alpha$-Fe. The spectra obtained were adjusted using the MOSF and DIST3E programs, the latter based on an independent distribution of hyperfine fields and/or quadrupole splittings. The numerical results of the adjustments are reported as hyperfine parameters, which are: hyperfine magnetic field $\left(H_{\mathrm{hf}}\right)$, expressed in kOe; relative sub-spectral area $(S)$, in \%; quadrupole shift and/or splitting $\left(2 \varepsilon_{\mathrm{Q}}, \Delta E_{\mathrm{Q}}\right)$; and isomer shift $(\delta)$, in $\mathrm{mm} / \mathrm{s}$.

The hydrogels were characterized by thermogravimetric analysis (TGA) using a TA Instruments Q50 V6.4 Build 193 analyzer. About $10 \mathrm{mg}$ of sample was placed in a platinum capsule and heated under a nitrogen atmosphere, with flow of $100 \mathrm{~mL} / \mathrm{min}$, from $10^{\circ} \mathrm{C}$ to $950{ }^{\circ} \mathrm{C}$ at a heating rate of $20^{\circ} \mathrm{C} / \mathrm{min}$. The enabled observing the mass loss, and consequently the degradation of the hydrogels, at different temperature ranges.

\subsection{Determination of swelling degree (Q)}

For determination of $Q$, the dried hydrogels were first weighed on an analytic balance (average weight of approximately $100 \mathrm{mg}$ ) and then placed to swell in $90 \mathrm{~mL}$ of water. After each time interval " $t$ ", which varied up to $1 \mathrm{~h}$, the hydrogel samples were removed from the water and the surfaces were carefully dried to remove the excess water, after which they were weighed again. The $Q$ values of the different hydrogels were calculated with Eq. (1) [14].

$$
Q=\frac{\left(M_{\mathrm{t}}-M_{\mathrm{o}}\right) \times 100}{M_{\mathrm{o}}}
$$

where $M_{\mathrm{t}}$ is the mass of the hydrogel after swelling for time $t$, and $M_{\mathrm{o}}$ is the mass of the same sample after drying. 


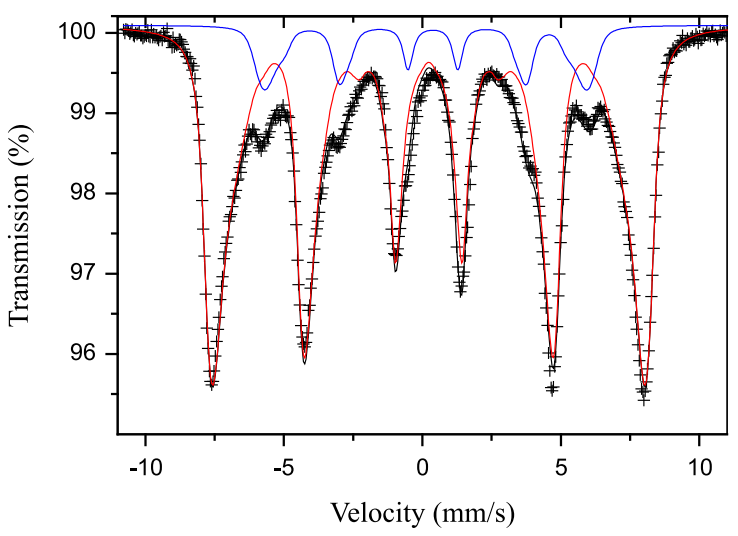

Fig. 2. Mössbauer spectrum of the pure magnetic material.
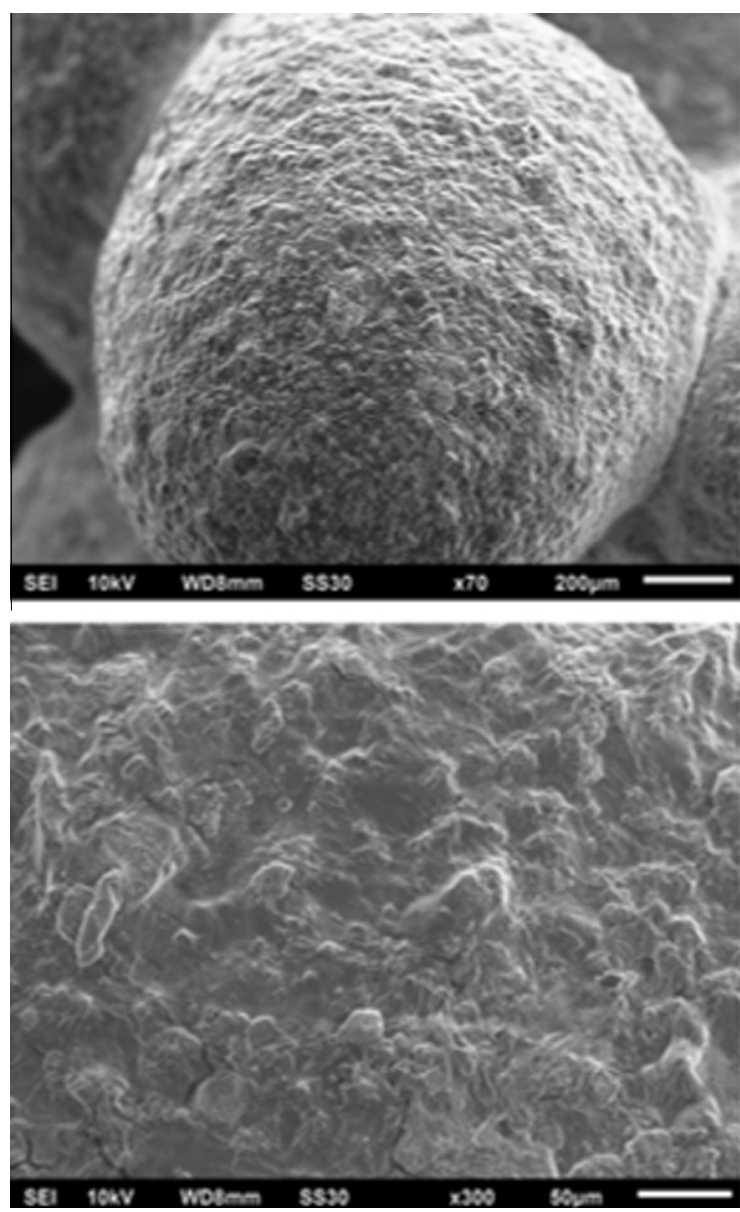

Fig. 3. SEM images of the magnetic hydrogel based on iota-carrageenan prepared with $\mathrm{CaCl}_{2}$ at $0.5 \mathrm{~mol} \mathrm{~L}^{-1}$.

\section{Results and discussion}

We first discuss the results of evaluating the nature of the synthesized magnetic material and then the properties of the hydrogels that were prepared.

The experiments were conducted in triplicate and the results shown are the medians. The hydrogels presented swelling degree of about $55 \%$. 

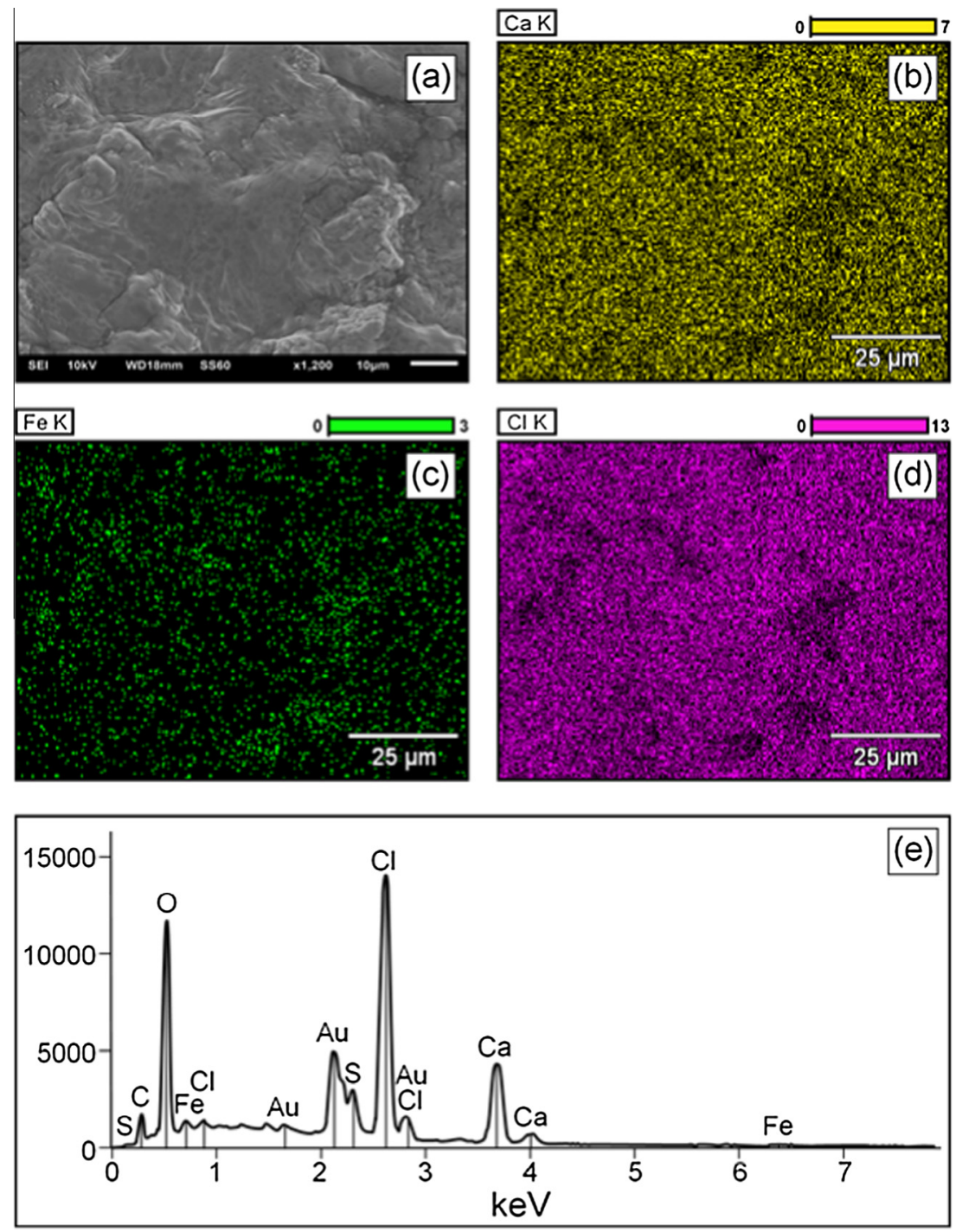

Fig. 4. (a) SEM image; (b) distribution of calcium; (c) distribution of chloride; (d) distribution of iron; and (e) EDX spectrum of the magnetic hydrogels based on iota-carrageenan prepared with $\mathrm{CaCl}_{2}$ at $0.5 \mathrm{~mol} \mathrm{~L}^{-1}$.

\subsection{Magnetic material}

The Mössbauer spectrum (Fig. 2) showed that the magnetic material synthesized in this study was composed basically of maghemite (outer sextet), with a small amount of goethite (inner sextet). This was indicated by the values of the magnetic fields and relative areas: $487 \mathrm{kOe}$ and 87\% (typical of maghemite); and $363 \mathrm{kOe}$ and 13\% (typical of goethite), respectively. The other hyperfine parameters (isomer shifts and quadrupole shifts) also pointed to these phases.

According to the literature $[15,16,19,20]$, the Mössbauer spectrum obtained for samples of magnetic iron oxide precipitated with $\mathrm{NH}_{4} \mathrm{OH}, \mathrm{NaOH}$ and $\mathrm{KOH}$ is formed by the sum of two magnetic sextets with broadened lines due to the nanometric character of the sample. These sextets may correspond to $\mathrm{Fe}^{3+}$ occupying the tetrahedral sites and octahedral sites in the cubic structure of maghemite, or to $\mathrm{Fe}^{3+}$ in tetrahedral sites and $\mathrm{Fe}^{2.5+}$ in the octahedral sites of magnetite [21]. The hyperfine parameters obtained in the present study indicates that the synthesized magnetic material is maghemite $\left(\gamma-\mathrm{Fe}_{2} \mathrm{O}_{3}\right)$.

The FTIR results indicate the composition of the synthesized magnetic material. The spectrum presented the main characteristic bands: $\mathrm{O}-\mathrm{H}$ (stretching bands of $\mathrm{Fe}-\mathrm{OH}$ at $3400 \mathrm{~cm}^{-1}$ ). The $\mathrm{OH}-\left(\right.$ broad band near $1632 \mathrm{~cm}^{-1}$ ) is related to the presence of water in the structure. Besides this, two bands between 630 and $550 \mathrm{~cm}^{-1}$ can be attributed to the Fe-O stretching of the $\gamma-\mathrm{Fe}_{2} \mathrm{O}_{3}$ and $\alpha-\mathrm{Fe}_{2} \mathrm{O}_{3}$ phases, respectively, confirming the presence of iron oxide. 

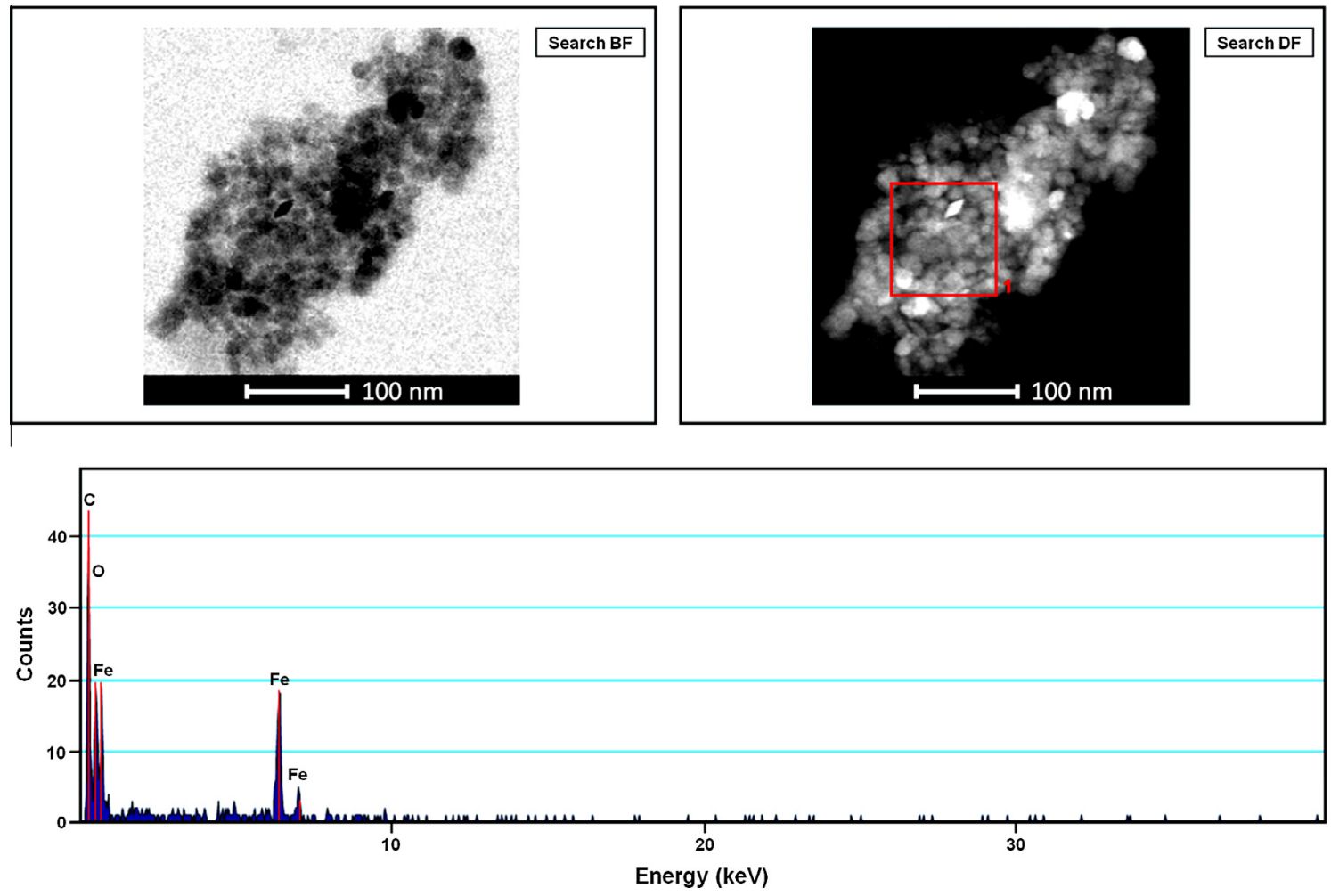

Fig. 5. TEM image (a) and EDX spectrum (b) of the magnetic hydrogel.

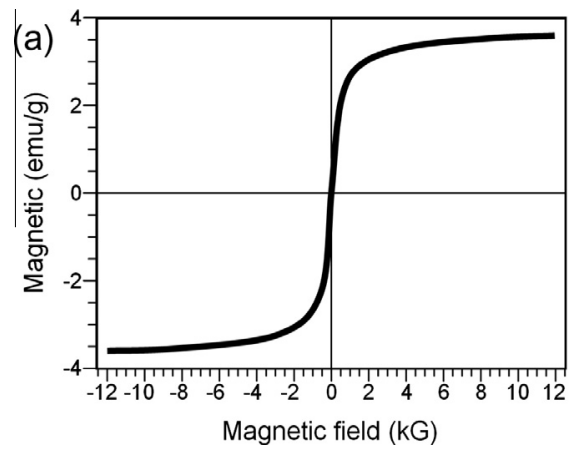

(b)

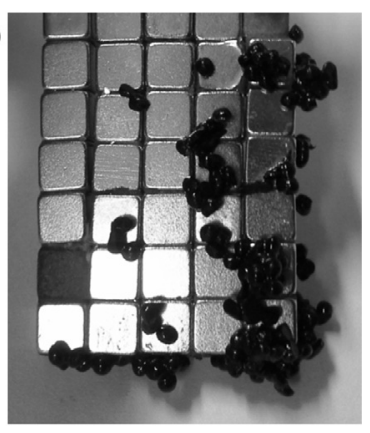

Fig. 6. VSM curve of the hydrogel (a) and digital image of the hydrogel samples responding to stimulus from a magnet (b).

\subsection{Evaluation of the hydrogels' morphological properties}

No hydrogels were formed in the experiments where the iota-carrageenan solution was added dropwise in the CaCl $\mathrm{Solu}$ tion at a concentration of $0.3 \mathrm{~mol} \mathrm{~L}^{-1}$. This probably occurred because the biopolymer iota-carrageenan contains a greater number of $\mathrm{SO}_{3}^{-}$groups in its chain (Fig. 1). Therefore, the number of $\mathrm{Ca}^{2+}$ ions present in the crosslinker solution was probably insufficient to crosslink the polymer to form a hydrogel.

In contrast, the dropwise addition of the iota-carrageenan solution in the $\mathrm{CaCl}_{2}$ solution at 0.5 mol $\mathrm{L}^{-1}$ formed hydrogels with particle size close to $710 \mu \mathrm{m}$. These hydrogels tended to contain particles with non-uniform shape. As mentioned in the literature, increasing the concentration of the crosslinking agent can influence the shape of hydrogel particles. Spherical particles are associated with tangential crosslinks that occur immediately after the addition of each droplet of the biopolymer solution that enters the crosslinker solution [22].

The scanning electron micrographs revealed that the hydrogel surface was relatively irregular, having a granulated layer covering the entire sample, probably due to the crosslinking agent (Fig. 3). 

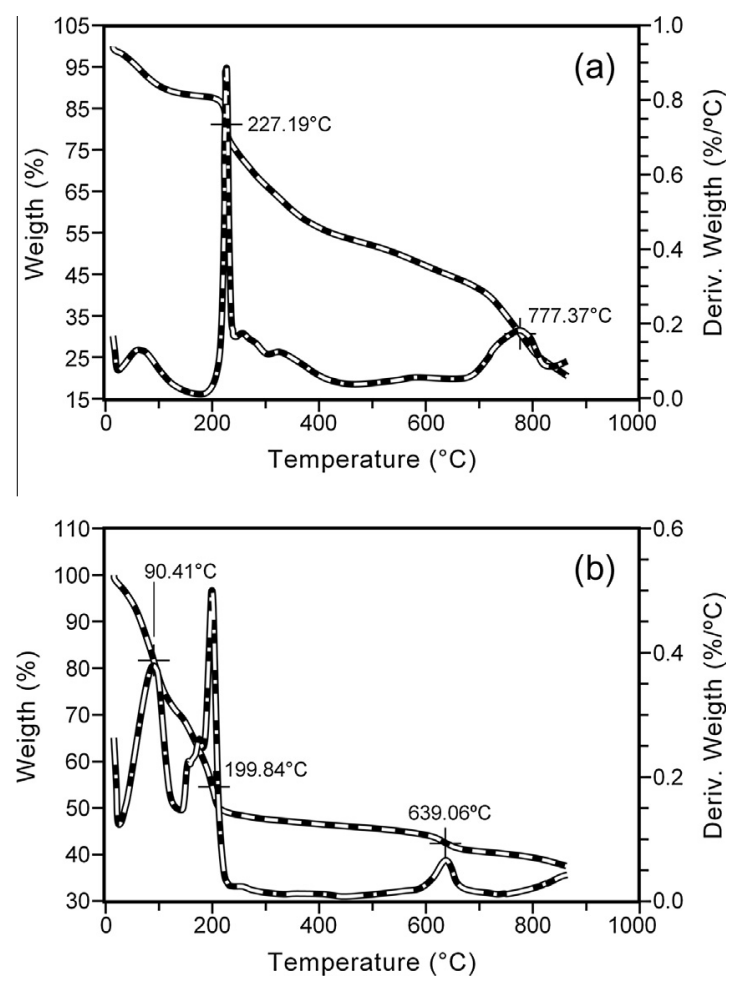

Fig. 7. TG and DTG of pure iota-carrageenan (a), and the magnetic hydrogel crosslinked with $\mathrm{CaCl}_{2}$ (b).

The composition maps and energy dispersive X-ray (EDX) spectra of the hydrogels (Fig. 4) showed that the microspheres had good distribution of calcium and chloride over the entire surface, proving that the irregularities (granulated layer) occurred due to the presence of the particles of the crosslinking agent $\left(\mathrm{CaCl}_{2}\right)$. This demonstrates the occurrence of a crosslinking reaction of iota-carrageenan with $\mathrm{Ca}^{2+}$ ions. The element iron was also well distributed on the hydrogel surface. These results corroborate the formation of magnetic hydrogels of iota-carrageenan crosslinked with $\mathrm{CaCl}_{2}$ at a concentration of $0.5 \mathrm{~mol} \mathrm{~L}^{-1}$.

The transmission electron microscope (TEM) images and EDX spectra (Fig. 5) proved that the magnetic iron oxide particles were dispersed in the hydrogels with nanometric size $(<50 \mathrm{~nm})$, confirming the formation of a nanocomposite with superparamagnetic behavior $[8,23]$.

\subsection{Evaluation of the hydrogels' chemical composition}

The FTIR analyses of the pure iota-carrageenan and the magnetic hydrogels were performed in the interval from 4000 to $600 \mathrm{~cm}^{-1}$. The spectra indicated the presence of functional groups of the biopolymer: $\mathrm{C}=\mathrm{C}$ (band at $1634 \mathrm{~cm}^{-1}$ ), characteristic of cyclical chain interactions; S-O (broad band between 1225 and $1152 \mathrm{~cm}^{-1}$ ), characteristic of ester sulfate interactions; galactose-4-sulfate (broad bands at $842 \mathrm{~cm}^{-1}$ ); pyranose sulfate (broad bands at $699 \mathrm{~cm}^{-1}$ ); $\mathrm{S}-\mathrm{O}$ (asymmetric sulfate stretching in the range of $1010-1070 \mathrm{~cm}^{-1}$ ); $\mathrm{C}-\mathrm{O}$ and $\mathrm{C}-\mathrm{OH}$ (elongation in the interval $845-850 \mathrm{~cm}^{-1}$ ); and $\mathrm{C}-\mathrm{O}-\mathrm{S}$ (elongation of $\alpha(1,3)$-D-galactose at $805 \mathrm{~cm}^{-1}$ ) [24].

\subsection{Evaluation of the hydrogels' magnetic properties}

The VSM curve (Fig. 6a) demonstrates that the hydrogels did not present a hysteresis cycle, a phenomenon that causes a delay between the magnetic flux density and the magnetic field. The remanent magnetization $\left(M_{R}\right)$ value was near zero $(0.1882 \mathrm{emu} / \mathrm{g})$, indicating the hydrogels had superparamagnetic characteristics. Finally, the saturation magnetization $\left(M_{\mathrm{S}}\right)$ was $2.9623 \mathrm{emu} / \mathrm{g}$ and the coercivity magnitude $\left(H_{\mathrm{C}}\right)$ was $29.5373 \mathrm{emu} / \mathrm{g}$.

In this study, even the hydrogel samples with low saturation magnetization responded well the stimulus from a magnet (Fig. 6b), confirming they can be classified as magnetic hydrogels. 


\subsection{Evaluation of the hydrogels' thermal properties}

The TG and DGT curves of pure iota-carrageenan are presented in Fig. 7a. The first mass loss stages corresponded to loss of the water in the biopolymer (characteristic of its hydrophilicity), in the temperature range of $0-200{ }^{\circ} \mathrm{C}$. The second mass loss occurred due to degradation of the polymer chains, with the maximum degradation speed of this stage corresponding to $T_{\max } \cong 227^{\circ} \mathrm{C}$ (Fig. 7a).

Fig. $7 \mathrm{~b}$ shows the TG and DTG curves of the hydrogel. The mass loss stage associated with degradation of the polymer chains presented $T_{\max } \cong 200{ }^{\circ} \mathrm{C}$. The last degradation stage (between 600 and $750{ }^{\circ} \mathrm{C}$ ) for the hydrogel corresponded to the degradation of compounds generated during previous stages.

The $T_{\max }$ value of the hydrogel was lower than the temperature for the pure iota-carrageenan. That result was not expected, since the hydrogel has crosslinked polymer chains, which should have caused greater thermal resistance. This might have happened due to the presence of the magnetic material. The $\gamma-\mathrm{Fe}_{2} \mathrm{O}_{3}$ might have influenced the crosslinking of the polymer chains, causing a reduction of the polymer's $T_{\max }$.

\section{Conclusion}

The magnetic material synthesized was mainly composed of maghemite $\left(\gamma-\mathrm{Fe}_{2} \mathrm{O}_{3}\right)$. We prepared magnetic hydrogels based on iota-carrageenan crosslinked with $\mathrm{CaCl}_{2}\left(0.5 \mathrm{~mol} \mathrm{~L}^{-1}\right)$. In the SEM imaging, the magnetic hydrogels showed relatively spherical morphology with irregular surface. The granulometric analysis indicated the average particle size of the hydrogels was near $710 \mu \mathrm{m}$. The hydrogels presented good thermal stability and swelling degree values in water of around $55 \%$. Both the magnetic nanoparticles and crosslinking agent $\mathrm{CaCl}_{2}$ were well distributed on the hydrogel surfaces. The magnetic hydrogels responded to stimulation from a magnet.

\section{Acknowledgments}

We are thankful to the Carlos Chagas Filho Research Foundation of the State of Rio de Janeiro (FAPERJ) and the National Council for Scientific and Technological Development (CNPq) for financial support.

\section{Appendix A. Supplementary material}

Supplementary data associated with this article can be found, in the online version, at http://dx.doi.org/10.1016/j.eurpolymj.2016.01.043.

\section{References}

[1] V.K. Thakur, M.K. Thakur, Recent trends in hydrogels based on psyllium polysaccharide: a review, J. Cleaner Prod. 82 (2014) 1-15, http://dx.doi.org/. 10.1016/j.jclepro.2014.06.066.

[2] V.K. Thakur, M.K. Thakur, P. Raghavan, M.R. Kessler, Progress in green polymer composites from lignin for multifunctional applications: a review, ACS Sustain. Chem. Eng. 2 (2014) 1072-1092, http://dx.doi.org/10.1021/sc500087z.

[3] V.K. Thakur, M.K. Thakur, Recent advances in green hydrogels from lignin: a review, Int. J. Biol. Macromol. 72 (2015) 834-847, http://dx.doi.org/ 10.1016/j.ijbiomac.2014.09.044.

[4] A. Pappua, V. Patil, S. Jain, A. Mahindrakar, R. Haquea, V.K. Thakur, A. Pappu, Advances in industrial prospective of cellulosic macromolecules enriched banana biofibre resources: a review, Int. J. Biol. Macromol. 79 (2015) 449-458, http://dx.doi.org/10.1016/j.ijbiomac.2015.05.013.

[5] V.K. Thakur, M.R. Kessle, Self-healing polymer nanocomposite materials: a review, Polymer 69 (2015) 369-383, http://dx.doi.org/10.1016/j. polymer.2015.04.086.

[6] V.K. Thakur, M.K. Thakur, Recent advances in graft copolymerization and applications of chitosan: a review, ACS Sustain. Chem. Eng. 2 (2014) 26372652, http://dx.doi.org/10.1021/sc500634p.

[7] R.A. Pedroso, I.M. Demiate, Evaluation of the influence of starch and carrageenan on the physicochemical and sensory characteristics of cooked turkey ham, Food Sci. Technol. 28 (2008) 24-31, http://dx.doi.org/10.1590/S0101-20612008000100005.

[8] T. Jayaramudu, G.M. Raghavendra, K. Varaprasad, R. Sadiku, K. Ramam, K.M. Raju, Iota-carrageenan-based biodegradable Ag ${ }^{0}$ nanocomposite hydrogels for the inactivation of bacteria, Carbohydr. Polym. 95 (2013) 188-194, http://dx.doi.org/10.1016/j.carbpol.2013.02.075.

[9] V.D. Prajapati, P.M. Maheriya, G.K. Jani, H.K. Solanki, Carrageenan: a natural seaweed polysaccharide and its applications, Carbohydr. Polym. 105 (2014) 97-112, http://dx.doi.org/10.1016/j.carbpol.2014.01.067.

[10] L. Li, R. Ni, Y. Shao, S. Mao, Carrageenan and its applications in drug delivery, Carbohydr. Polym. 103 (2014) 1-11, http://dx.doi.org/10.1016/ j.carbpol.2013.12.008.

[11] V.L. Campo, D.F. Kawano, D.B. Silva Jr., I. Carvalho, Carrageenans: biological properties, chemical modifications and structures analysis: a review, Carbohydr. Polym. 77 (2009) 167-180, http://dx.doi.org/10.1016/j.carbpol.2009.01.020.

[12] A.L. Daniel-da-Silva, R. Lóio, J.A. Lopes-da-silva, T. Trindade, B.J. Goodfellow, A.M. Gil, Effects of magnetite nanoparticles on the thermorheological properties of carrageenan hydrogels, J Colloid Interface Sci 324 (2008) 205-211, http://dx.doi.org/10.1016/j.jcis.2008.04.051.

[13] A. Pourjavadi, Sh. Barzegar, F. Zeidabadi, Synthesis and properties of biodegradable hydrogels of k-carrageenan grafted acrylic-acid-co-2-acrylamido2-methylpropanesulfonic acid as candidates for drug delivery systems, React. Funct. Polym. 67 (2007) 644-654, http://dx.doi.org/10.1016/j. reactfunctpolym.2007.04.007.

[14] M.F. Nazarudin, A.A. Shamsurf, M.N. Shamsudin, Preparation and physicochemical evaluation of biodegradable magnetic k-carrageenan beads and application for chromium ions pre-concentration, J. Chil. Chem. Soc. 56 (2011) 891-894, http://dx.doi.org/10.4067/S0717-97072011000400015.

[15] L. León, A. Bustamante, A. Osório, G.S. Olarte, L.S. Valladares, C.H.W. Barnes, Y. Majima, Synthesis and characterization of hollow $\alpha$-Fe $\mathrm{O}_{3}$ sub-micron spheres prepared by sol-gel, Hyperfine Interact. 202 (2011) 131-137, http://dx.doi.org/10.1007/s10751-011-0353-1.

[16] D. Maity, D.C. Agrawal, Synthesis of iron oxide nanoparticles under oxidizing environment and their stabilization in aqueous and non-aqueous media, J. Magn. Magn. Mater. 308 (2007) 46-55, http://dx.doi.org/10.1016/j.jmmm.2006.05.001. 
[17] A.M. Salgueiro, A.L. Daniel-da-Silva, S. Fateixa, T. Trindade, K-Carrageenan hydrogel nanocomposites with release behavior mediated by morphological distinct Au nanofillers, Carbohydr. Polym. 91 (2013) 100-109, http://dx.doi.org/10.1016/j.carbpol.2012.08.004.

[18] M. Pasquale, C.P. Sasso, M. Velluto, S.H. Lim, Stress sensing with Co based ferrite composites, J. Magn. Magn. Mater. 242 (2002) 1460-1463, http://dx. doi.org/10.1016/S0304-8853(01)01103-9.

[19] G.M. Costa, E. Grave, R.E. Vandenberghe, Mössbauer studies of magnetite and Al-substituted maghemite, Hyperfine Interact. 117 (1998) $207-243$, http://dx.doi.org/10.1023/A:1012691209853.

[20] R.E. Vandenberghe, C.A. Barrero, G.M. Costa, E. Van San, E. De Grave, Mössbauer characterization of iron oxides and (oxy)hydroxides: the present state of the art, Hyperfine Interact. 126 (2000) 247-259, http://dx.doi.org/10.1023/A:1012603603203.

[21] G.M. Costa, C.B. Andujar, E. Grave, Q.A. Pankhurst, Magnetic nanoparticles for in vivo use: a critical assessment of their composition, J. Phys. Chem. B 118 (2014) 11738-11746, http://dx.doi.org/10.1021/jp5055765.

[22] E.G. Popa, M.E. Gomes, R.L. Reis, Cell delivery systems using alginate-carrageenan hydrogel beads and fibers for regenerative medicine applications, Biomacromolecules 12 (2011) 3952-3961, http://dx.doi.org/10.1021/bm200965x.

[23] T. Mitsumata, N. Abe, Giant and reversible magneto rheology of carrageenan/iron oxide magnetic gels, Smart Mater. Struct. 20 (2011) 124003-124005, http://dx.doi.org/10.1088/0964-1726/20/12/124003.

[24] H. Salimi, A. Pourjavadi, F. Seidi, P.E. Jahromi, R. Soleyman, New Smart Carrageenan-based Superabsorbent Hydrogel Hybrid: Investigation of Swelling Rate and Environmental Responsiveness, Wiley InterScience, 2010, pp. 1-11. 